\title{
Protocol for qRT-PCR analysis from formalin fixed paraffin embedded tissue sections from diffuse large b-cell Iymphoma: Validation of the six-gene predictor score
}

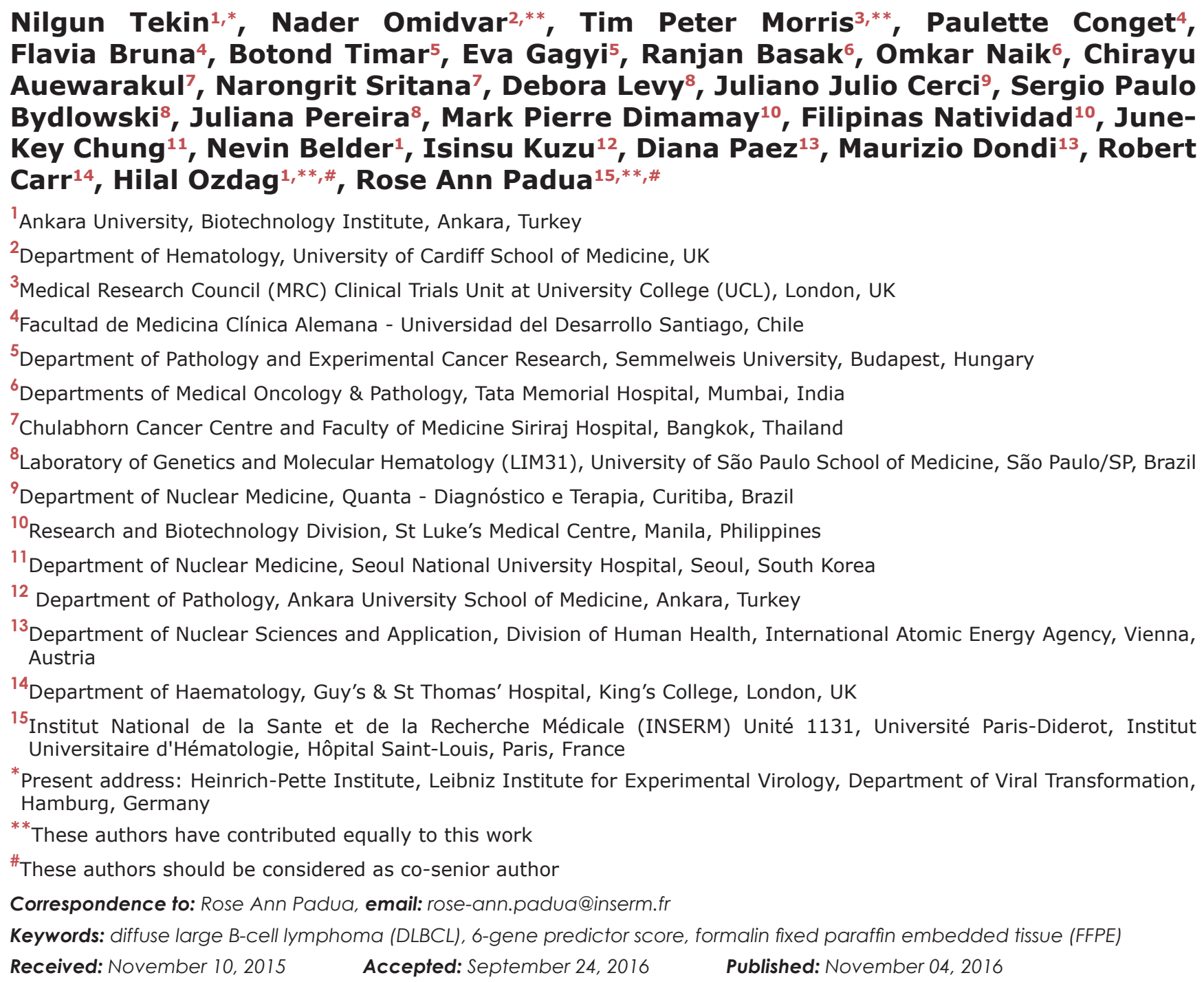

\section{ABSTRACT}

As a part of an international study on the molecular analysis of Diffuse Large B-cell Lymphoma (DLBCL), a robust protocol for gene expression analysis from RNA extraction to qRT-PCR using Formalin Fixed Paraffin Embedded tissues was developed. Here a study was conducted to define a strategy to validate the previously reported 6-gene (LMO2, BCL6, FN1, CCND2, SCYA3 and BCL2) model as predictor of prognosis in DLBCL. To avoid variation, all samples were tested in a single centre and single platform. This study comprised 8 countries (Brazil, Chile, Hungary, India, Philippines, S. Korea, Thailand and Turkey). Using the Kaplan-Meier and log rank test on patients $(n=162)$ and two mortality risk groups (with those above and below the mean representing high and low risk groups) confirmed that the 6-gene predictor 
score correlates significantly with overall survival $(O S, p<0.01)$ but not with event free survival (EFS, $p=0.18$ ). Adding the International Prognostic Index (IPI) shows that the 6-gene predictor score correlates significantly with high IPI scores for OS $(p<0.05)$, whereas those with low IPI scores show a trend not reaching significance $(p=0.08)$. This study defined an effective and economical $q R T-P C R$ strategy and validated the 6-gene score as a predictor of OS in an international setting.

\section{INTRODUCTION}

Curing cancer has become a global priority. Optimizing cure rates requires accurate diagnosis for the selection of the most appropriate treatment, and increasingly this involves genetic subtyping of the disease for both diagnosis and prognostic stratification. Global gene expression alteration is common and found to be correlated with the clinical outcome of cancer. Identification of genes with altered expression level provides valuable information regarding the diagnosis, prognosis and treatment of cancer. Recently high throughput, genome-wide expression profiling (GEP) analyses indicated that some of these genes can be used as marker genes providing important diagnostic and prognostic information about the disease [1,2].

Diffuse large B-cell lymphoma (DLBCL) is the most frequent lymphoma in adults worldwide. Patients with DLBCL can be risk-stratified on the basis of their clinical characteristics, biological sub classification of the tumor based on gene or antigen expression, and speed of response to treatment based on positron emission tomography (PET) monitoring. Lossos et al. using a univariate analysis of microarray GEP data, identified 6 genes (LMO2, BCL6, FN1, CCND2, SCYA, BCL2) from a potentially informative 36 gene panel whose expression had been reported to predict survival [3]. By analyzing the expression of these 6 genes by RT-PCR in 66 patients at the time of diagnosis, they showed that the activation status of these genes correlated with patient overall survival (OS), and was independent of the International Prognostic Index (IPI) score. When this 6-gene data was combined with the clinical IPI at diagnosis, a high predictive index of outcome was achieved. This resulted in a 6-gene model designed to predict outcome in individual patients independent of the IPI, which was validated in two datasets $[4,5]$. However, the risk stratification data reported had been generated from Western populations. It is unclear how applicable this would be to predicting clinical outcomes in non-European, non-US populations [6].

As the primary purpose of this project was to inform management of DLBCL in middle income countries across diverse ethnic populations, the first step of this study was to identify an optimum and robust methodology from RNA extraction to real-time quantitative reversetranscription (qRT-PCR) analysis, for routine cancer gene expression profiling. A gene expression analysis protocol starts with RNA isolation and extends to the analysis of qRT-PCR data. qRT-PCR is the most sensitive method for quantifying gene expression. The robustness of this technique is directly correlated with the integrity and quality of RNA, the choice of detection chemistry (hydrolysis probes, fluorescent hairpins or intercalating dyes) and methods to analyse the data (relative vs. absolute). Thus, a robust gene expression analysis protocol from RNA isolation to qRT-PCR is crucial.

To this end, we investigated different methodologies for quantifying informative gene expression in DLBCL. We used the validated 6-gene model to measure whether the methods compared achieved equivalent outputs and assessing whether the 6-gene model was applicable in an international setting.

\section{RESULTS}

\section{RNA isolation}

The purity of the extracted RNA from formalin fixed paraffin embedded (FFPE) tissues was assessed by OD 260/280 with minimum and maximum values 1.52 and 2.16 respectively. Minimum and maximum RNA concentration were determined as $47.29 \mathrm{ng} / \mu \mathrm{l}$ and 4385.38 $\mathrm{ng} / \mu \mathrm{l}$ respectively.

\section{High volume vs low volume cDNA synthesis comparisons}

The workflow for protocol optimization is illustrated (Figure S1). In this study in order to evaluate the impact of cDNA synthesis efficiency on the relative quantification results two cDNA synthesis protocols were followed. The first protocol was the one recommended in the ABI High Capacity cDNA Reverse Transcription Kit. The synthesis volume of this protocol was $20 \mu \mathrm{l}$, which was then diluted 10 times with sterile $\mathrm{ddH}_{2} \mathrm{O}$. The modified protocol synthesis volume is $100 \mu 1$. Both cDNA synthesis protocols starting RNA amount was $1000 \mathrm{ng}$. The number of samples processed with both protocols and both chemistries was shown (Supplementary Tables S1 and S2).

In order to assess the efficiency, reproducibility and robustness of these two cDNA synthesis protocols the triplicate $\mathrm{Ct}$ measurement was analyzed using linear mixed models, and using the graphics described in the methods section. The high volume cDNA synthesis method consistently gave lower $\mathrm{Ct}$ with lower variation within the triplicates for $A B L, B C L 2, B C L 6, C C N D 2, F N 1, L M O 2$ and SCYA3 using the Taqman chemistry (Figure 1A). 
The delta delta $\mathrm{Ct}$ values for the 6 genes and 6-gene scores of low and high volume synthesis show that they are equivalent after normalizations to the housekeeping gene ABL and Raji/NLN (Figure 1B and 1C).

\section{Taqman vs SYBR green comparison}

Amplifications of the same targets using Taqman or SYBR Green chemistries were compared (Figure S2). The

A
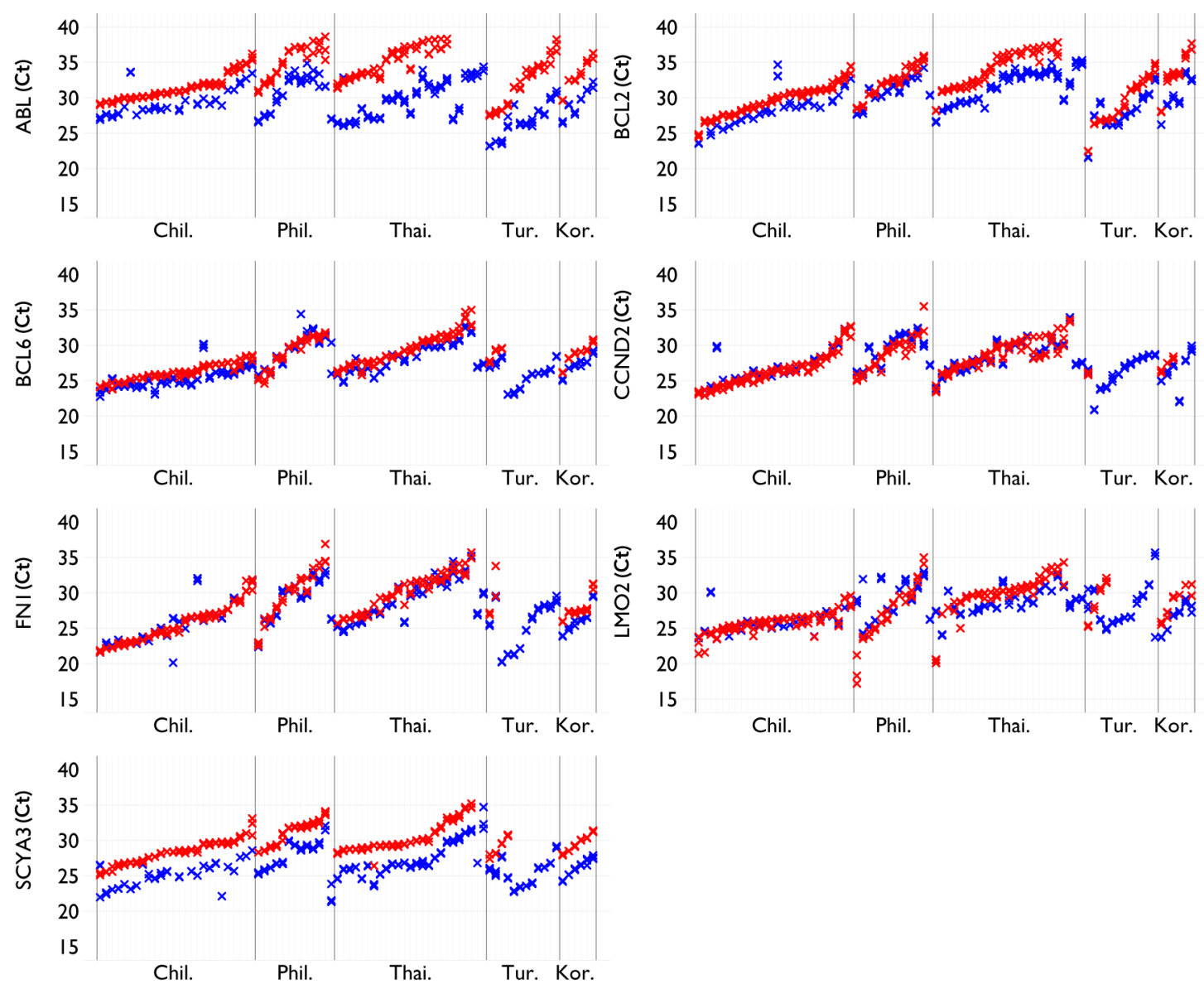

B Normalised $\Delta \Delta C$ t values across the 6-genes using Low-
or High-volume cDNA synthesis

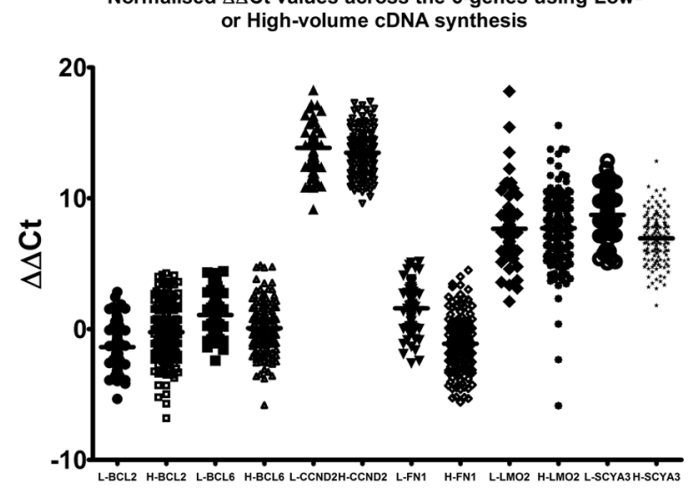

C

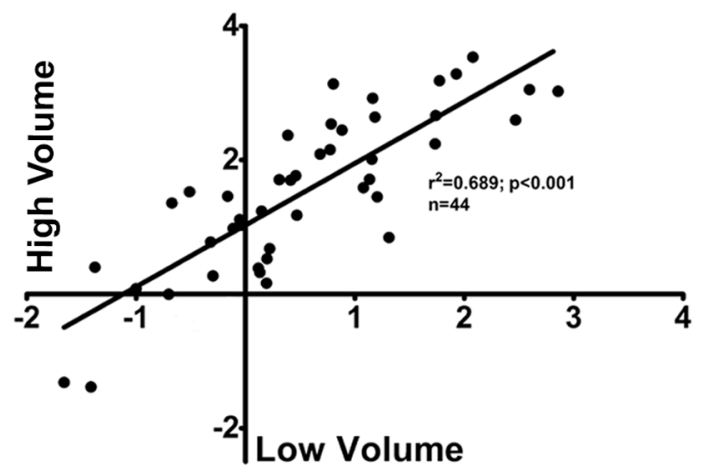

Figure 1: Low versus high volume cDNA synthesis. A. High volume (blue) consistently gives lower Ct values than low volume (red) for most genes and most samples using Taqman chemistry; B. Normalized delta delta Ct values show that low and high volume datasets are equivalent $(\mathrm{n}=44)$; C. Positive correlation was observed in samples where both low- and high volumecDNA synthesis was applied $(\mathrm{p}<0.001, \mathrm{n}=44)$. 
SYBR Green and Taqman chemistries with the calculated data according to the expression ratio based on efficiency corrected Delta $\mathrm{Ct}$ [7] using the plasmid standard curve efficiency show a good correlation (Figure S2A and S2B); the $\mathrm{Ct}$ values are concordant between the two chemistries (Figure S2C).

\section{Standard curves}

Expression ratio based on efficiency corrected Delta $\mathrm{Ct}$ [7] were separately calculated with the efficiency values obtained from the Raji cell line, plasmid and Normal Lymph Nodes (NLN) standard curves for the each gene. Comparisons of plasmid vs the Raji cell line or plasmid vs NLN standard curves were undertaken by plotting one measurement against the other, and then using plotting the limits of agreement. There was a high agreement between the three different templates (Figure S3 and S4). While using the standard curve from the serial dilutions of the Raji cell line, the standard curve for FN1 and CCND2 genes could not be generated due to high $\mathrm{Ct}$ values (above $\mathrm{Ct} 35$ ) because of their low expression in the Raji cell line. There was a high compatibility between the Raji cell line and plasmid standard curves for the genes BCL2, LMO2, $B C L 6$ and SCYA3 (Figures S4A and S4B). In contrast to standard curves from the Raji cell line, standard curves for the 6 genes were successfully generated from the NLN cDNA. There was a high correlation between NLN and plasmid standard curves for the six genes (Figures S4C and S4D).

\section{Copy number vs Ct based calculation comparison}

Relative expression was calculated using the same data set and three different methods namely: copy number ratio, delta delta $\mathrm{Ct}$, Pfaffl's equation with using the efficiency of plasmid DNA [7]. Comparisons show that all three methods are concordant (Figure S5). There was a high compatibility between Delta Delta $\mathrm{Ct}$ and Copy number ratio (Figure S5A and S5B). The compatibility between Pfaffl's equation and Copy number ratio is shown (Figure S5C and S5D).

\section{Validation of 6-gene model}

The 'mortality predictor' score as described by Lossos et al and modified by Malumbres et al for FFPE sections, based on LMO2, BCL6, FN1, CCND2, SCYA3, and $B C L 2$, was applied to patients in our study [3]. A positive correlation was observed in the predictor score where both low and high volume data was available (Figure $1 \mathrm{C} ; \mathrm{r}^{2}=0.689, \mathrm{p}<0.001, \mathrm{n}=44$ ). The expanded data set incorporating multiple imputational analysis was next employed, where the overall-survival returned a hazard ratio of 0.35 (95\% CI $0.17-0.74)$. This demonstrates that the score predicts relative survival well. The patients were ranked according to mortality predictor score and were divided in high $(\mathrm{n}=81)$, and low risk $(\mathrm{n}=81)$ groups based on the weighted expression of the 6 genes [8]. The 6-gene predictor model showed that OS was significantly longer in the low risk group as compared to that of the high risk (Figure $2 \mathrm{~A}, \mathrm{p}<0.01$ ); whereas EFS was not statistically significantly different between the two risk groups (Figure $2 \mathrm{~B} ; \mathrm{p}=0.18$ ). To evaluate the prognostic value of the 6-gene model we next performed survival analysis in patients with high and low IPI scores. The OS of high risk vs low patients as defined by the 6-gene score, was significantly different in patients defined as high risk by the IPI (Figure $3 \mathrm{~A} ; \mathrm{p}<0.05$ ), but not in low risk IPI patients (Figure 3B; $\mathrm{p}=0.08$ ). No difference was observed within our cohort between CHOP versus R-CHOP treatment regimens in terms of OS (Figure $\mathrm{S} 6 \mathrm{~A} ; \mathrm{p}=0.41$ ) or EFS (Figure S6B; $p=0.66$ ). Furthermore, within the R-CHOP treated cohort, we did not observe a significant difference between the low- versus high- risk groups in terms of OS (Figure S7A; $\mathrm{p}=0.06$ ) or EFS (Figure S7B; $p=0.19$ ). Hans algorithm where available are shown in Table1; no significant difference was found between GCB vs non-GCB in our cohort (OS p=0.65; EFS $p=0.92$ ).

\section{DISCUSSION}

The aim of this international study was to define a robust, sensitive and reproducible strategy to identify the expression profile of the 6-gene model and to validate the six-gene predictor score for outcome in DLBCL. Due to the increasing use of qRT-PCR in the diagnostic and prognostic setting and the necessity to use FFPE tissue for analysis we have developed a robust protocol. It is important to optimize the cDNA synthesis step and to note that most manufacturers recommend low volume cDNA synthesis method. It would appear that, due to the reproducibility of the triplicates and reduced $\mathrm{Ct}$ values of high volume cDNA synthesis, the high volume synthesis is superior to the low volume synthesis using the Taqman chemistry (Figure 1). This profile is lost with the SYBR Green reactions possibly due to the larger amplicon size. This is particularly important when dealing with the low quality of RNA we expect from paraffin-derived tissues. However, with the NLN derived RNA, which would be of good quality, the high volume cDNA consistently gave lower $\mathrm{Ct}$ values for all of the amplicons tested. However, normalizations ensured that the delta delta $\mathrm{Ct}$ values and 6-gene scores were finally equivalent.

The two most commonly used chemistries of Taqman and SYBR Green correlate well. The difference in cost between these reagents has precluded the use of Taqman reagents in resource poor settings; this study shows that SYBR Green method can substitute for Taqman well. However, the optimal amplicon size for SYBR Green is around $300 \mathrm{bp}$ whereas for Taqman it is $100 \mathrm{bp}$, 
therefore for FFPE derived degraded RNA Taqman is the chemistry of choice both for size and specificity with the use of an internal probe.

Standard curves generated from the plasmid and cellular derived cDNAs are equivalent and therefore the copy number method, which relies on generating a plasmid derived standard curve correlates with the delta delta $\mathrm{Ct}$ and efficiency corrected $\mathrm{Ct}$ method. This study shows that it is not necessary to clone every target under investigation for obtaining relative quantities and comparing data from

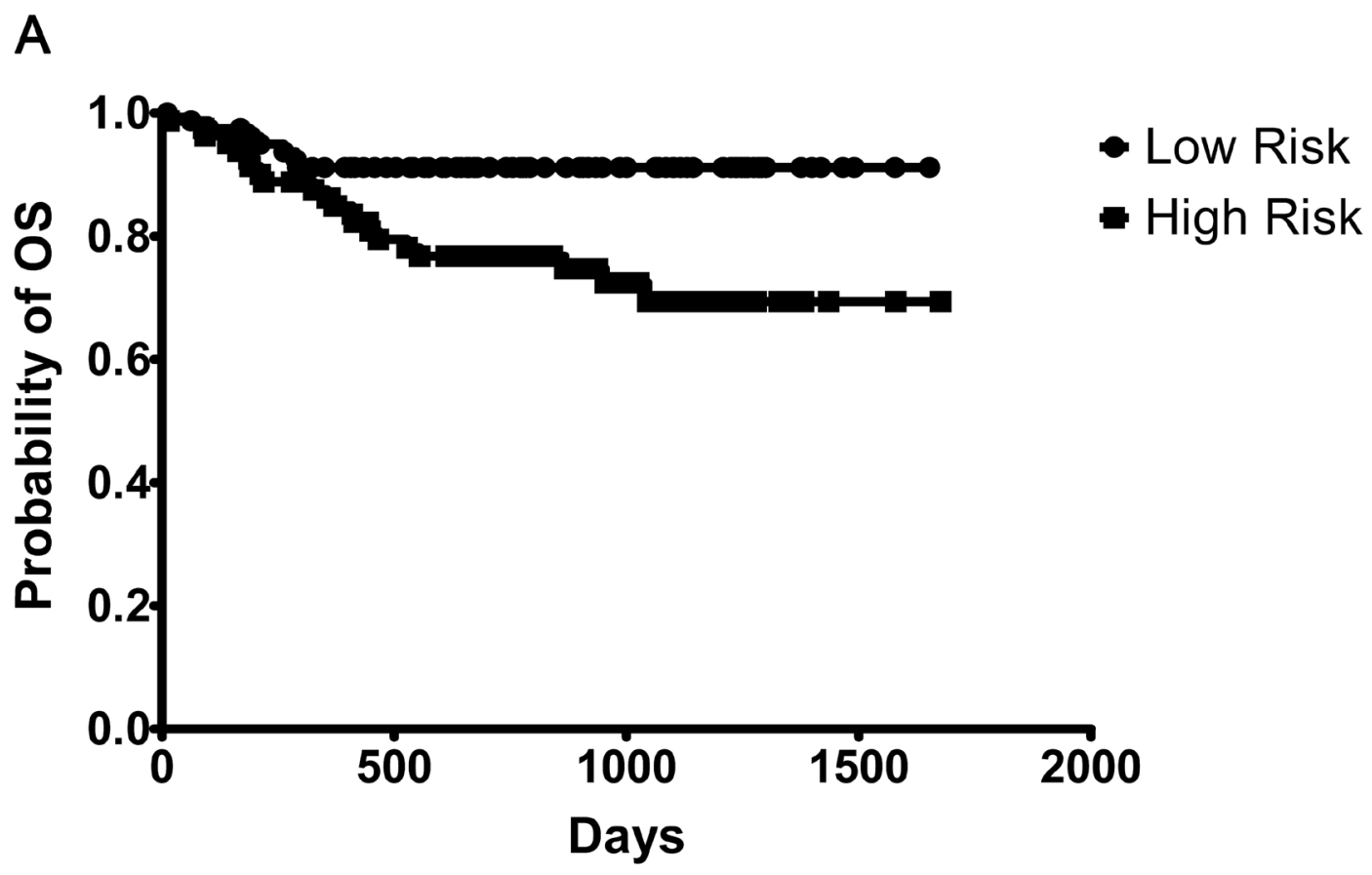

B

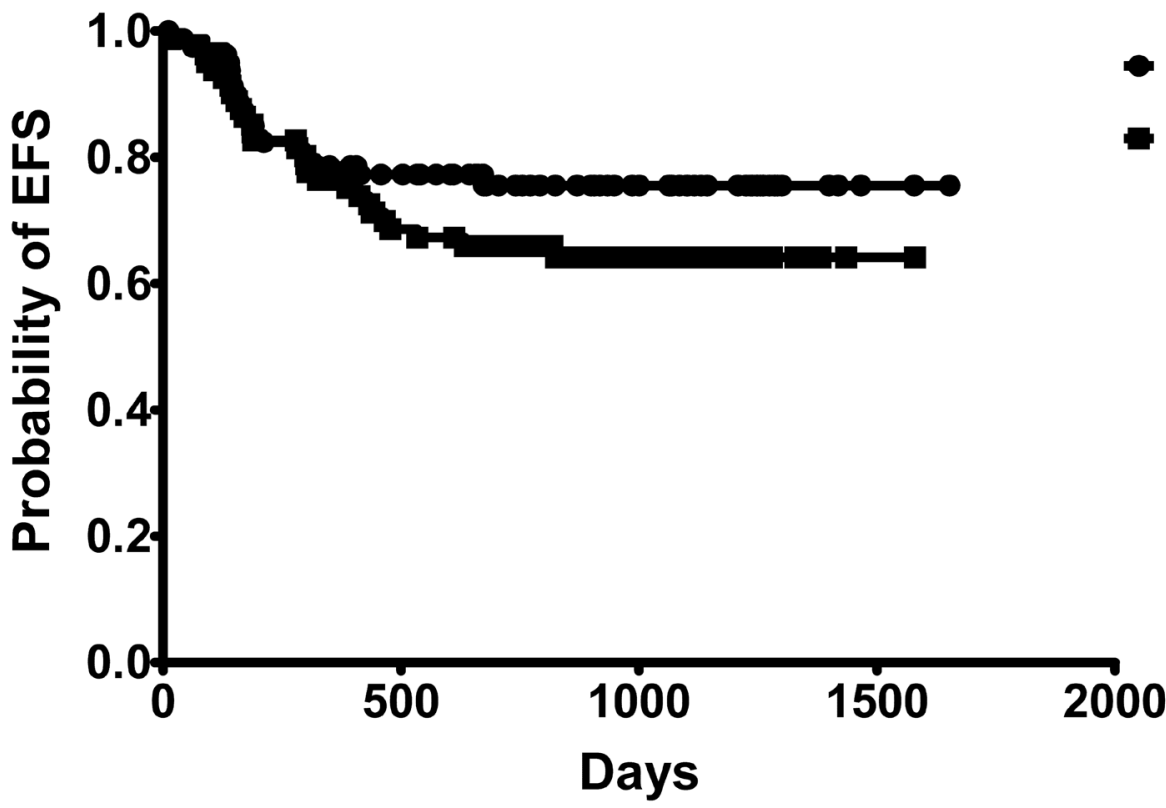

Figure 2: Six-gene model predicts overall survival (OS) in diffuse large B-cell lymphoma (DLBCL) patients treated with Rituximab, cyclophosphamide, doxorubicin (hydroxydaunomycin), vincristine (Oncovin ${ }^{\circledR}$ ), prednisolone (a steroid) (R-CHOP) and CHOP chemotherapy within an international multi-centre setting. Kaplan-Meier curves of 162 patients. A. show significant extended OS of low risk patients as defined by 6-gene predictor score $(\mathrm{p}<0.01$; patient numbers Low $n=81$, High $n=81)$; B. show no significant EFS of low risk patients as defined by the 6-gene predictor score $(\mathrm{p}=0.18$; patient numbers Low $\mathrm{n}=81$, High $\mathrm{n}=81$ ). 
different plates; one can use standard curves derived from a reference cell line. However, to obtain absolute values, it remains necessary to use plasmid derived standard curves. At the end of these optimization steps we concluded that high volume cDNA synthesis, use of Taqman chemistry should be the protocol to follow in especially FFPE derived RNA samples. Here in this international study we have developed a robust, sensitive and reproducible qRTPCR strategy suitable for the limited budgets available in middle-income countries, from RNA extraction up to data

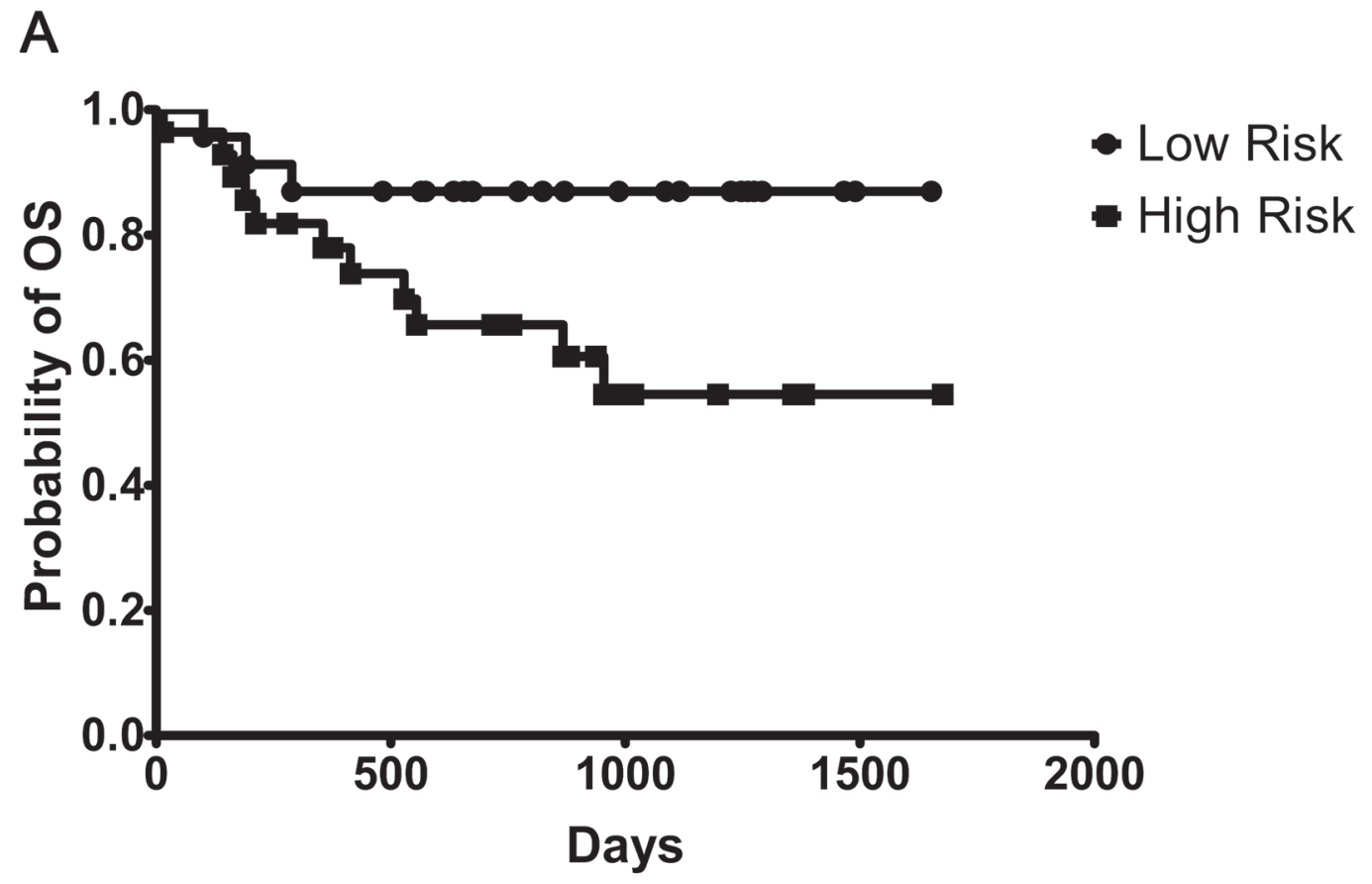

B

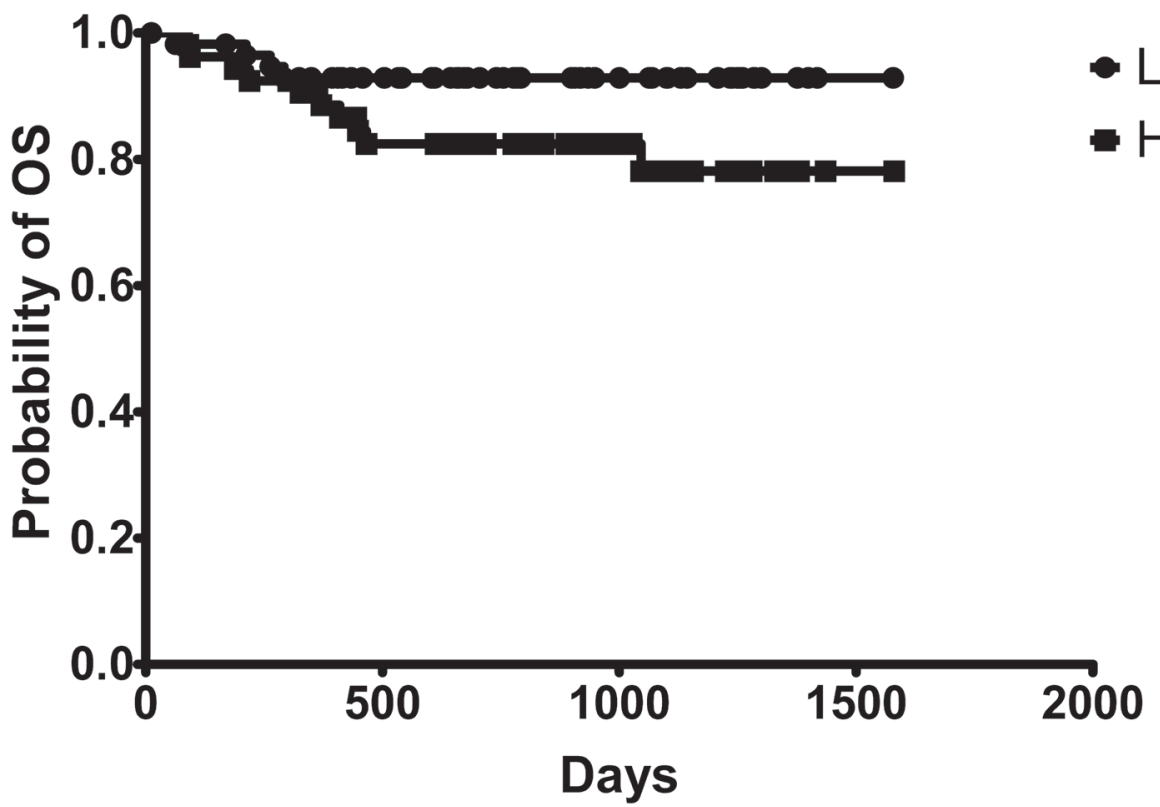

Figure 3: Six-gene predictor model is independent of the International Prognostic Indicator (IPI). A. Significant difference is observed in Kaplan-Meier curves of overall survival (OS) based on 6-gene predictor score in high clinical risk patients (IPI score 3-5, $\mathrm{n}=51)(\mathrm{p}<0.05)$; Patient numbers Low $\mathrm{n}=23$, High $\mathrm{n}=28$; B. no significant difference in Kaplan-Meier curves of OS in low clinical risk patients (IPI score 0-2, $\mathrm{n}=111)(\mathrm{p}=0.08)$; Patient numbers Low $\mathrm{n}=58$, High $\mathrm{n}=53$. 
analysis to identify the expression profile of the six gene model.

As with the Malumbres study, where FFPE tissue was used, this international study returned a significant association between the 6-gene predictor score and OS. When added to IPI the 6-gene score was significantly associated with high IPI score and not low IPI score, whereas the Malumbres study was significantly associated with low IPI and not high [8]. This suggests that both studies would benefit from increased sample size. In an international setting involving patients from 8 countries, 3 continents and different ethnic backgrounds our study has demonstrated that the 6 gene score can add some prognostic information to patients with a high clinical risk index, validating this model as a prognosticator in DLBCL, illustrating the utility of molecular expression studies.

\section{MATERIALS AND METHODS}

\section{Patients}

The International Atomic Energy Agency (IAEA) sponsored a prospective study of DLBCL in countries from 8 United Nations geographical regions. Patient samples were obtained from clinical centres in the countries detailed in Table 1. The local ethics committee approved the study and informed consent was obtained from all patients. Consented patients with DLBCL $(n=162)$ in Brazil $(n=18)$, Chile $(n=27)$, Hungary $(n=28)$, India $(n=27)$, South Korea $(n=7)$, Philippines $(n=13)$, Thailand $(n=27)$, and Turkey were treated with a mixture of rituximab, cyclophosphamide, doxorubicin (hydroxydaunomycin), vincristine (Oncovin (), prednisolone (a steroid) (R-CHOP) (83\%) or CHOP (17\%) between 2008 and 2013. Diagnosis was made by country representative pathologists and the diagnostic criteria was set up in a collaborative meeting (Ankara). Hans algorithm was used for immunohistochemical subclassification (CD10, Bcl6, MUM1). This method and markers are accepted as gold standard and reliable for the subclassification. These patients were a subset of the cohort of a Coordinated Research Project funded by the IAEA where the use of interim PET was investigated in order to risk stratify patients [9]. CD20 immunohistochemistry was performed for all of the cases for indication of anti CD20 therapy.

\section{RNA isolation}

Total RNA was extracted from FFPE tissues (five sections (10 $\mu \mathrm{m}$ thickness) using Qiagen FFPE Rneasy Kit (Qiagen Cat \#74404, Valencia, CA, USA) with a modified deparaffinization step [10]. Briefly, sections were deparaffinized by 2 repeated incubations in xylene for 10 minutes, followed by 2 repeated incubations in
$100 \%$ ethanol for 5 minutes and then were washed with distilled water for 30 seconds. After deparaffinization, the remaining steps of RNA extraction were followed according to the Qiagen FFPE RNeasy Kit manual. All RNA samples were analyzed spectrophotometrically on a Nanodrop (NanoDrop 1000 Spectrophotometer V3.7, Thermo Fisher Scientific Inc, Wilmington, DE, USA).

\section{cDNA synthesis}

Two different cDNA synthesis methods were evaluated. The integrity of the cDNA templates was evaluated using the Fusion Quant ${ }^{\circledR}$ standard ABL (reference: CGRS-01-4, Ipsogen, France) and subsequently qRT-PCR was carried out on the 7 target genes with Taqman and in a subset, SYBR Green chemistry (Table S1 and Table S2).

\section{Molecular cloning of the target genes}

The target genes (LMO2, BCL6, FN1, CCND2, $S C Y A 3$ ) were amplified (primer details in Supplementary Table S3) and cloned into the $\mathrm{TOPO}^{\circledR}$ vector and transformed to chemically competent E.coli cells (provided by the Kit) according to the manufacturer's instructions (Invitrogen TOPO TA Cloning Kit Cat No.K4510-20, Carlsbad, CA, USA). Plasmid DNA was purified with QIAprep Spin Miniprep Kit (Cat No.27104 Hilden, Germany) according to the manufacturer's instructions. To confirm the cloning, PCR reactions were repeated for target genes from plasmid DNA minipreps and then sent for sequencing. The $B C L-2$ plasmid was already available [11].

\section{Low volume}

1000 ng RNA was used to synthesize using the ABI High Capacity cDNA Reverse Transcription Kit (Cat. 4368813 Foster City, CA, USA) in a total volume of 20 $\mu 1$. This cDNA sample was then diluted to $100 \mu \mathrm{l}$ and 2 $\mu \mathrm{l}$ (20 ng) is used per each qRT-PCR reaction (according to the kit user instructions). Samples from Brazil were synthesized only with the low volume protocol.

\section{High volume}

1000 ng RNA was used to synthesize using ABI High-Capacity cDNA Reverse Transcription in a total volume of $100 \mu \mathrm{l}$. The reaction volume was equal to 5 times of the original reaction mix with $1000 \mathrm{ng}$ RNA. $2 \mu \mathrm{l}$ $(20 \mathrm{ng} / \mu \mathrm{l}) \mathrm{cDNA}$ samples directly used per each qRT-PCR reaction.

\section{qRT-PCR analysis}

Standard curves were prepared from plasmids containing cloned target genes (BCL-2, LMO2, BCL6, $F N 1$, CCND2, SCYA3) that were amplified (method details in supplementary methods information, cloning primer details in Table S3 and SYBR green primers in Table 


\section{TOTAL}

\begin{tabular}{|c|c|}
\hline Number of Patients & 162 \\
\hline Sex M & $\begin{array}{c}83 \\
(51 \%)\end{array}$ \\
\hline $\begin{array}{l}\text { Age at Diagnosis } \\
\text { Median (quartiles) }\end{array}$ & $\begin{array}{c}55 \\
(46,66)\end{array}$ \\
\hline $\begin{array}{l}\text { IPI Score } \quad 0-1 \\
\qquad \begin{array}{l}2 \\
3 \\
4-5\end{array}\end{array}$ & $\begin{array}{l}75(46 \%) \\
37(23 \%) \\
33(20 \%) \\
17(11 \%)\end{array}$ \\
\hline $\begin{array}{l}\text { GCB/non-GCB/unknown } \\
\text { (\% non-GCB where known) }\end{array}$ & $56 / 76 / 30(47 \%)$ \\
\hline $\begin{array}{l}\text { Mean } 2 \text { y Outcomes (days) [range] } \\
(95 \% \mathrm{CI})\end{array}$ & $\begin{array}{c}\text { OS: } 538 \\
{[480-596]} \\
\text { EFS: } 423 \\
{[366-481]}\end{array}$ \\
\hline $\begin{array}{l}\text { R-CHOP } \\
\text { CHOP }\end{array}$ & $\begin{array}{c}134(83 \%) \\
28(17 \%)\end{array}$ \\
\hline $\begin{array}{l}\text { Chemotherapy } \\
\text { Cycles: } \quad<6 \\
6 \\
>6\end{array}$ & $\begin{array}{l}19(12 \%) \\
84(52 \%) \\
59(36 \%)\end{array}$ \\
\hline $\begin{array}{l}\text { Consolidation Radiotherapy } \\
\text { Total } \\
\text { (Bulky disease) } \\
\text { (Non-bulky site) }\end{array}$ & $\begin{array}{c}42(28 \%) \\
(38) \\
(4)\end{array}$ \\
\hline Number of patients with significant $\mathrm{Rx}$ delays or dose reductions & $\begin{array}{c}23 / 100(23 \%) \\
(48 \text { not known) }\end{array}$ \\
\hline
\end{tabular}

rituximab, cyclophosphamide, doxorubicin (Hydroxydaunomycin), vincristine (oncovin ${ }^{\circledR}$ ), prednisolone (a steroid) (R-CHOP).

S4). Taqman qRT-PCR assays were conducted on a Light Cycler 480 (Roche, Mannheim, Germany) platform using Life Technologies Applied Biosystems Taqman Gene Expression Assays according to the kit user instructions (BCR ABL1 Hs99999002_mH, BCL2 Hs00153350_ m1, BCL6 Hs00277037_m, CCND2 Hs00277041_ m1, FN1 Hs00365058_m1, LMO2 Hs00277106_m, SCYA3 Hs00234142_m1, TNFRSF9 Hs00155512_m1) and TaqMan ${ }^{\circledR}$ Universal PCR Master Mix (Applied Biosystems, Foster City, CA, USA) Cat. 4304437). Expression ratios were calculated based on delta delta $\mathrm{Ct}$ : $\mathrm{R}=2^{(-\Delta \Delta \mathrm{CT})}[7]$.

\section{Copy number of the plasmids}

Dilutions were calculated for copy numbers of $10^{8}-10^{3}$ for each of the 8 plasmids $[12,13]$. All qRTPCRs were undertaken using a 384-plate Roche LC480 instrument (Roche, Mannheim, Germany) at the Ankara University Biotechnology Institute Central Laboratory by one investigator. Most of RNA extractions and the cDNAs were done at Ankara University by the investigators from the participating countries. qRT-PCRs were done from plasmid DNAs of the target genes to generate standard curves with the Power SYBR ${ }^{\circledR}$ Green PCR Master Mix (Life Technologies, Applied Biosystems, Cat.No. 4367659, Carlsbad, CA) according to the manufacturer's instructions. Formula;

$$
N=\frac{\text { Cplasmid }}{A} \cdot 1,07085.10^{15}
$$

$\mathbf{N}$ : Copy number (copies/ $\mu \mathrm{l})$

C plasmid: Concentration of the plasmid DNA $(\mu \mathrm{g} / \mu \mathrm{l})$

A: Size of the plasmid with insert (bp)

\section{Standard curves}

Standard curves were derived from plasmids, Raji cell line and a normal lymph node (NLN) pool from FFPE 
sections. For plasmids serial dilutions from $10^{8}$ to $10^{3}$ copies were prepared. For the Raji and NLN 6x 10 fold serial dilutions were prepared from the original cDNA stock ( $1 \mu \mathrm{g}$ RNA in $100 \mu \mathrm{l}$ synthesis reaction for high volume and $1 \mu \mathrm{g}$ RNA in $20 \mu \mathrm{l}$ for low volume). qRT-PCR reactions were performed.

\section{SYBR green reactions}

Target genes BCL2, BCL6, CCND2, FN1, LMO2, $S C Y A 3$ and $A B L$ qRT-PCR analysis were conducted on a Light Cycler 480 platform using ABI Power SYBR Green PCR Master Mix (Applied Biosystems Cat. 4367659, Foster City, CA, USA). Primer sequences, annealing temperatures and amplicon sizes for the seven target genes and ABL housekeeping gene $[14,15]$ are listed in Supplementary Table S3. Briefly PCR conditions are $94^{\circ} \mathrm{C}$ for $3 \mathrm{~min}, 30$ cycles of $94^{\circ} \mathrm{C} 30 \mathrm{sec}$, appropriate annealing temperature for $30 \mathrm{sec}$, and $72^{\circ} \mathrm{C}$ for $30 \mathrm{sec}$. Followed by a melting program.

\section{Expression ratios and statistical analysis}

Relative quantifications were carried out using three different approaches detailed below and comparative analyses were undertaken.

Expression Ratio Based on Normalized Copy Numbers [16]

$$
\begin{array}{r}
R=\frac{\text { Patient Target Gene Copy No }}{\text { Patient ABL Copy No }} / \\
\frac{\text { Control Target Gene Copy No }}{\text { Control ABL Copy No }}
\end{array}
$$

\section{Expression Ratio Based on Efficiency Corrected Delta Ct [7]}

$$
R=\frac{E_{\text {Target Gene }}{ }^{(\text {ControlCt-PatientCt })}}{E_{A B L}^{(\text {ControlCt-PatientCt })}}
$$

E: Efficiency

Ct: threshold cycle Ct [17]

Expression Ratio Based on Efficiency Delta Delta

$R=2^{(-\Delta \Delta C T)}$

\section{Validation of the 6-gene model}

As an independent study with measurements on the six-genes score used by Lossos et al and modified by Malumbres et al (LMO2, BCL6, FN1, CCND2, SCYA3 and $B C L 2$ ) validation of the scores was performed [3]. For the prognostic score analysis samples with ABL Ct values $>37$ were not included. This cut off was determined from standard curves generated with target genes cloned into plasmids by running an absolute quantification. Thus, as seen from the Figure $\mathrm{S} 8$ the log copy number of ABL of the samples at this low range correlates with $\mathrm{ABL} C \mathrm{Ct}$. Ct 37 corresponds to 9-15 copies, which is within the limits of detection for this assay, which has a cut off of $<3$ copies [18-20]. As raw Ct values may vary between samples, delta $\mathrm{Ct}$ values were compared to FFPE normal lymph node samples. The samples acceptance criteria was based upon the Minimum Information for Publication of Quantitative Real-Time PCR Experiment) (MIQE) guidelines [18] as well as the determined PCR efficiency for each assay using FFPE NLN for ABL and all six genes (all 95.5\%-99.5\%).

As the original scores were based on data using low volume cDNA synthesis, the initial analysis using separate multiple imputation of low-volume \& high-volume data and the Lossos predictor formula was undertaken $(n=162$ patients) $[3,21]$. The normalized gene-expression values were log-transformed (on a base of 2) and the mortality predictor score was calculated based on the following equation: Mortality Predictor Score $=(-0.0273 x L M O 2)+$ $(-0.2103 \times$ BCL- 6$)+(-0.1878 \times \mathrm{FN} 1)+(0.0346 \mathrm{xCCND} 2)+$ $(0.1888 \times$ SCYA 3$)+(0.5527 x B C L-2)$ [3]. This score was categorically ranked which allowed their division into two mortality risk groups with those above and below the mean representing high and low risk groups [8]. Unlike the original Lossos study, where fresh tissue was used, the Malumbres method used FFPE tissue, similar to this current study. OS was defined as the time interval between the date of diagnoses to the date of death or last follow-up. Event free survival was defined as the time interval between the date of initial diagnosis and date of disease progression or death from any cause, whichever came first, or date of last follow-up evaluation. Survival curves were estimated using the product-limit method of Kaplan-Meier and were compared using the log-rank test. Multivariate regression analysis according to the Cox proportional hazards regression model [22] with OS or EFS as the dependent variables, was used to adjust for the effect of the Mortality Predictor Score and IPI. The t-test or Pearson's Chi-squared test were used to compare the clinical characteristics between the low and high risk patient groups of the 6-gene model. $\mathrm{p}<0.05$ was considered significant. Statistical analyses were carried out in Stata, GraphPad Prism and SPSS.

\section{ACKNOWLEDGMENTS}

This research was supported as Coordinated Research Project with the project number E1.50.20 by the IAEA. We acknowledge the contributions of the following haemato/oncologists who provided the clinical samples 
and patient details and follow-up: Patricia Fardella (Chile), Tamás Masszi (Hungary), Andrea Sipos (Hungary), Reena Nair (India), Noppadol Siritanaratkul (Thailand), Renata Cost (Brazil), Maejoy Vena Campo (Philippines), Sunyang Park (Korea), Muhit Ozcan (Turkey) and Sally Babikir (IAEA) for administrative assistance.

\section{Authorship}

NT performed experiments, analyzed data and wrote the manuscript

TM and NO did the statistical analysis and wrote the manuscript

PC, FB, BT, EG, RB, ON, CA, NS, DL, SPB, JP, MPD, FN, J-K, NB, and IK performed experiments and corrected the manuscript

HO \& RAP designed experiments, analyzed data and wrote the manuscript

The study was conceived by RAP and RC, DP and MD oversaw the study for the IAEA.

\section{CONFLICTS OF INTEREST}

The authors declared no conflicts of interest.

\section{REFERENCES}

1. Chung $\mathrm{CH}$, Bernard PS, Perou CM. Molecular portraits and the family tree of cancer. Nat Genet. 2002; 32:533-40. doi: $10.1038 /$ ng 1038 .

2. Liotta L, Petricoin E. Molecular profiling of human cancer. Nat Rev Genet. 2000; 1:48-56. doi: 10.1038/35049567.

3. Lossos IS, Czerwinski DK, Alizadeh AA, Wechser MA, Tibshirani R, Botstein D, Levy R. Prediction of survival in diffuse large-B-cell lymphoma based on the expression of six genes. N Engl J Med. 2004; 350:1828-37. doi: 10.1056/ NEJMoa032520.

4. Rosenwald A, Wright G, Chan WC, Connors JM, Campo E, Fisher RI, Gascoyne RD, Muller-Hermelink HK, Smeland EB, Giltnane JM, Hurt EM, Zhao H, Averett L, et al. The use of molecular profiling to predict survival after chemotherapy for diffuse large-B-cell lymphoma. N Engl J Med. 2002; 346:1937-47. doi: 10.1056/NEJMoa012914.

5. Shipp MA, Ross KN, Tamayo P, Weng AP, Kutok JL, Aguiar RC, Gaasenbeek M, Angelo M, Reich M, Pinkus GS, Ray TS, Koval MA, Last KW, et al. Diffuse large B-cell lymphoma outcome prediction by gene-expression profiling and supervised machine learning. Nat Med. 2002; 8:68-74. doi: 10.1038/nm0102-68.

6. Ribeiro RC, Pui CH. Saving the children--improving childhood cancer treatment in developing countries. N Engl J Med. 2005; 352:2158-60. doi: 10.1056/NEJMp048313.

7. Pfaffl MW. A new mathematical model for relative quantification in real-time RT-PCR. Nucleic Acids Res. 2001; 29:e45. doi:
8. Malumbres R, Chen J, Tibshirani R, Johnson NA, Sehn LH, Natkunam Y, Briones J, Advani R, Connors JM, Byrne GE, Levy R, Gascoyne RD, Lossos IS. Paraffin-based 6-gene model predicts outcome in diffuse large B-cell lymphoma patients treated with R-CHOP. Blood. 2008; 111:5509-14. doi: 10.1182/blood-2008-02-136374.

9. Carr R, Fanti S, Paez D, Cerci J, Gyorke T, Redondo F, Morris TP, Meneghetti C, Auewarakul C, Nair R, Gorospe C, Chung JK, Kuzu I, et al. Prospective international cohort study demonstrates inability of interim PET to predict treatment failure in diffuse large B-cell lymphoma. J Nucl Med. 2014; 55:1936-44. doi: 10.2967/jnumed.114.145326.

10. Belder N, Coşkun O, Erdoğan BD, Dağ ÖI, Savaş B, Ensari A, Özdağ H. From RNA Isolation to Microarray Analysis Comparison of Methods in FFPE Tissues. Research and Practice. 2015; In press. doi:

11. Omidvar N, Kogan S, Beurlet S, le Pogam C, Janin A, West R, Noguera ME, Reboul M, Soulie A, Leboeuf C, Setterblad N, Felsher D, Lagasse E, et al. BCL-2 and mutant NRAS interact physically and functionally in a mouse model of progressive myelodysplasia. Cancer Res. 2007; 67:1165767. doi: 10.1158/0008-5472.CAN-07-0196.

12. Staroscik A. URI Genomics \& Sequencing Center. Calculator for determining the number of copies of a template. http://cels.uri.edu/gsc/cndna.html. Accessed online. July 2014.

13. Wende H. Critical Factors for Successful Real-Time PCR. http://www.ff.ul.pt/ mjgama/Critical_Factors_for_ Successful_Real-Time_PCR\%5B1\%5D.pdf. Accessed online July 12, 2014.

14. Beillard E, Pallisgaard N, van der Velden VH, Bi W, Dee $\mathrm{R}$, van der Schoot E, Delabesse E, Macintyre E, Gottardi E, Saglio G, Watzinger F, Lion T, van Dongen JJ, et al. Evaluation of candidate control genes for diagnosis and residual disease detection in leukemic patients using 'realtime' quantitative reverse-transcriptase polymerase chain reaction (RQ-PCR) - a Europe against cancer program. Leukemia. 2003; 17:2474-86. doi: 10.1038/sj.leu.2403136.

15. Gabert J, Beillard E, van der Velden VH, Bi W, Grimwade D, Pallisgaard N, Barbany G, Cazzaniga G, Cayuela JM, Cave H, Pane F, Aerts JL, De Micheli D, et al. Standardization and quality control studies of 'real-time' quantitative reverse transcriptase polymerase chain reaction of fusion gene transcripts for residual disease detection in leukemia - a Europe Against Cancer program. Leukemia. 2003; 17:2318-57. doi: 10.1038/sj.leu.2403135.

16. Cassinat B, Zassadowski F, Balitrand N, Barbey C, Rain JD, Fenaux P, Degos L, Vidaud M, Chomienne C. Quantitation of minimal residual disease in acute promyelocytic leukemia patients with $\mathrm{t}(15 ; 17)$ translocation using realtime RT-PCR. Leukemia. 2000; 14:324-8. doi:

17. ABI PRISM 7700 Sequence Detection System. User Bulletin \#2. http://docs.appliedbiosystems.com/ pebiodocs/04303859.pdf. Accessed online July 12, 2014. 
18. Bustin SA, Benes V, Garson JA, Hellemans J, Huggett J, Kubista M, Mueller R, Nolan T, Pfaffl MW, Shipley GL, Vandesompele J, Wittwer CT. The MIQE guidelines: minimum information for publication of quantitative realtime PCR experiments. Clin Chem. 2009; 55:611-22. doi: 10.1373/clinchem.2008.112797.

19. Waiblinger H-U, Graf N, Broll H, Grohmann L, Pietsch K. Evaluation of real-time PCR results at the limit of detection. Journal für Verbraucherschutz und Lebensmittelsicherheit. 2011; 6:411-7. doi: 10.1007/s00003-011-0669-4.
20. Nutz S, Doll K, Karlovsky P. Determination of the LOQ in real-time PCR by receiver operating characteristic curve analysis: application to qRT-PCR assays for Fusarium verticillioides and F. proliferatum. Anal Bioanal Chem. 2011; 401:717-26. doi: 10.1007/s00216-011-5089-x.

21. White IR, Royston P, Wood AM. Multiple imputation using chained equations: Issues and guidance for practice. Stat Med. 2011; 30:377-99. doi: 10.1002/sim.4067.

22. Royston P, Altman DG. External validation of a Cox prognostic model: principles and methods. BMC Med Res Methodol. 2013; 13:33. doi: 10.1186/1471-2288-13-33. 